\title{
ДЕЙСТВИЕ МЕХАНИЗМА ИНФЛЯЦИОННОЙ СПИРАЛИ В СОВРЕМЕННОЙ ЭКОНОМИКЕ РОССИИ
}

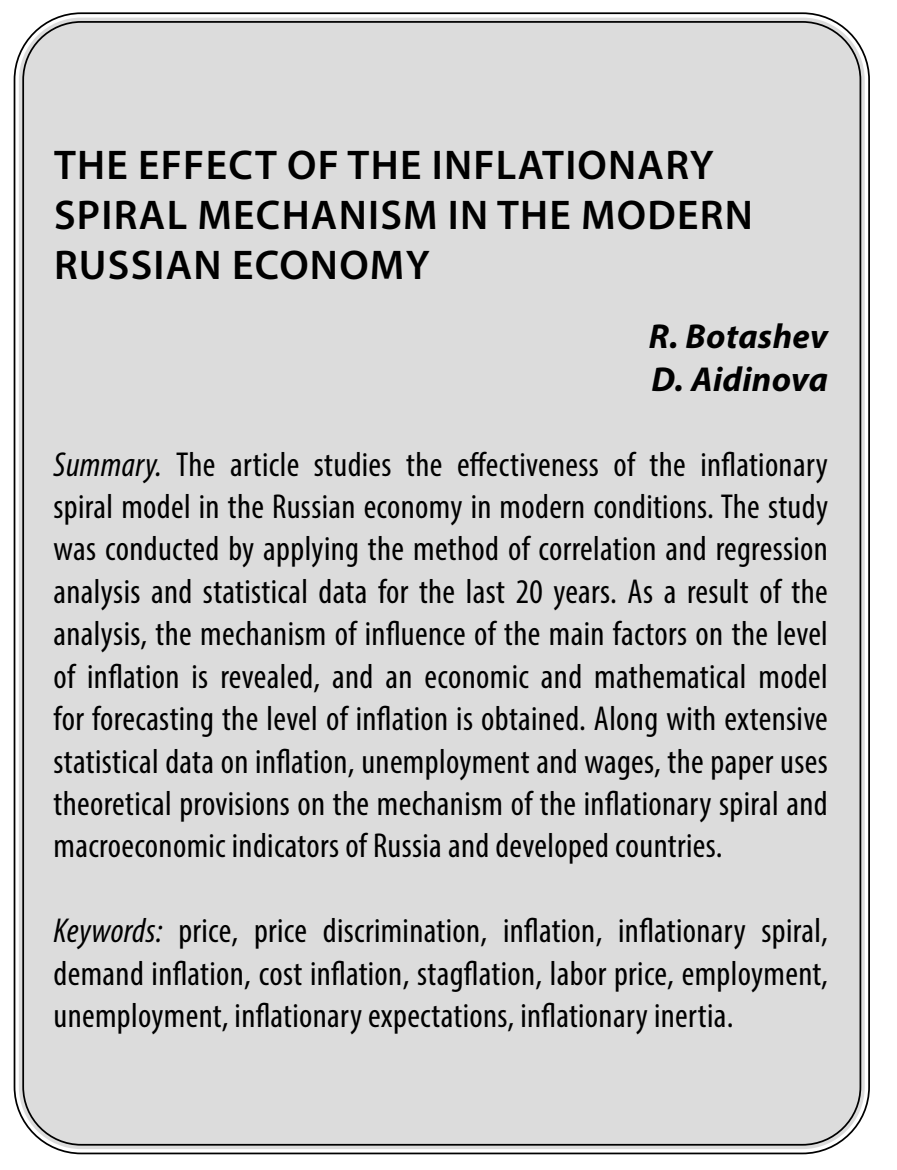

$\mathbf{K}$ ак известно, все государства, где действует рыночная экономическая система, сталкиваются с проблемой инфляции (inflation) в разной степени, которая проявляется в устойчивом росте общего уровня цен. Годовое увеличение цен может идти разными путями: быть незначительным и нарастать медленными темпами (ползучая инфляция) или быть существенным и набирающим темпы (гиперинфляция).

Дело в том, что инфляция - это сложный противоречивый процесс, который, как правило, вызывает серьезные социально-экономические последствия. Борьба с инфляцией всегда была и остается основной задачей макроэкономической политики государства, т.к. инфляция отрицательно влияет на все стороны экономической деятельности и уровень жизни населения. Особую сложность представляет собой выявление особенностей действия механизма инфляционной спирали в условиях страны с переходной экономикой как Россия.
Боташев Руслан Азаматович

Доцент, Карачаево-Черкесский государственный университет имени У.Д. Алиева, г. Карачаевск

botashevruslan@mail.ru

Айдинова Диана Хаджи-Муратовна

К.э.н., дочент, Карачаево-Черкесский государственный университет Имени У.Д. Алиева, г. Карачаевск diana.aidinova@mail.ru

Аннотация. В статье проводится исследование эффективности действия модели инфляционной спирали в экономике России в современных условиях. Исследование проведено путём применения метода корреляционно-регрессионного анализа и статистических данных за последние 20 лет. В результате анализа раскрыт механизм влияния основных факторов на уровень инфляции, а также получена экономико-математическая модель для прогнозирования уровня инфляции. Наравне с обширными статистическими данными об инфляции, о безработице и заработной плате в работе используются теоретические положения о механизме действия инфляционной спирали и макроэкономические показатели России и развитых стран.

Ключевые слова: цена, ценовая дискриминация, инфляция, инфляционная спираль, инфляция спроса, инфляция издержек, стагфляция, цена труда, занятость, безработица, инфляционные ожидания, инфляционная инерция.

Нетрудно догадаться, что переход экономики на рыночные отношения значительно повысил значение денег, а инфляция, как известно, в первую очередь снижает покупательную способность денег. Сегодня проблемы денежных отношений становятся основными вопросами по модернизации экономики страны. Как показывает опыт многих стран, переход на рыночные отношения, как правило, сопровождается быстрым ростом цен и усилением действия инфляционных факторов. Поэтому при проведении исследования причин инфляции очень важно, в первую очередь, правильно оценить, является ли переход на рыночные отношения причиной углубления инфляции. Может быть и такая ситуация, что накопленный ранее инфляционный потенциал получает теперь свое реальное выражение.

Следует отметить, что в условиях рыночных отношений у правительства страны резко сокращаются возможности искусственного сдерживания инфляции, а порою они становятся просто невозможными. Вместе с тем сле- 
дует заметить, что непоследовательность и непродуманность правительством страны некоторых шагов перехода к рынку, ещё сильнее усугубляют имеющиеся трудности и усиливают инфляционные процессы [1, с. 147].

Можно выделить две основные причины возникновения инфляции:

1. избыточный спрос на валовый национальный продукт при полном использовании производственных мощностей (Demand-pull inflation);

2. рост издержек на производство продукции (заработная плата, сырье и материалы, электроэнергия и т.д.) - Cost-push inflation.

Монетаристская школа учёных-экономистов утверждает, что инфляция спроса вызвана нерегулируемой эмиссией денег и предписывает строгий контроль над ростом денежной массы в качестве средства снижения избыточных расходов. За снижение расходов ратует кейнсианская школа. Представители этой школы рекомендуют это осуществить путем увеличения налогов и путём сокращения государственных расходов. При таком подходе инфляция издержек ассоциируется в основном с чрезмерным ростом номинальной заработной платы и внезапно возникающими при этом скачками цен на некоторые товары.

В настоящее время теория «инфляционных издержек» является наиболее распространенной теорией макроэкономического анализа. Ядром этой теории является модель инфляционной спирали: «заработная плата - цены». Инфляционная спираль (inflationary spiral of price-wage spiral), или спираль цен и заработной платы, связана с возникновением в 70-е годы XX столетия нового явления в теории инфляции, которую назвали «инфляцией экономических кризисов». Позднее это явление получило название «стагфляция».

С возникновением стагфляции зарубежные экономисты взялись за обоснование теории инфляционной спирали «заработная плата - цены», которая стала основой теории «инфляционных издержек». При этом инфляция учеными рассматривается в качестве результата давления спроса на рост издержек. В результате чрезмерное увеличение средней заработной платы по отношению к производительности труда вызывает новое повышение цен. В качестве основного способа подавления инфляции ими рекомендуется политика ограничения спроса и доходов рабочих [7, с.93].

Дело в том, что первоначальный резкий рост цен на товары и услуги, вызванный ростом затрат на сырье, может привести к тому, что профсоюзы станут требовать повышения номинальной заработной платы для поддержания уровня жизни рабочих. Если они доби- ваются удовлетворения своих требований, то производители повышают цены на свою продукцию с целью удержать прибыли. В свою очередь, новый рост цен снова влечёт за собой новое повышение заработной платы и т.д. В результате запуска механизм инфляционной спирали начинает сам себя раскручивать, т.е. можно утверждать, что механизм инфляционной спирали является механизмом самовоспроизводства инфляции.

На наш взгляд, инфляционная спираль формируется по следующему алгоритму:

1. в результате пересмотра условий трудового договора между наемными работниками и работодателями на рынке труда сначала происходит установление нового уровня заработной платы;

2. затем, как следствие, возникает изменение общего уровня заработной платы в масштабах национальной экономики. Если этот процесс на рынке труда не уравновешивается ростом производительности труда и другими факторами, то увеличение издержек на единицу продукции, как правило, приводит к сокращению производства товаров и услуг;

3. сокращение производства и, соответственно, предложения приведет к росту цен как следствие при увеличивающемся спросе;

4. рост цен, в свою очередь, дает новый импульс к переговорам между наемными работниками и работодателями о новом витке увеличения оплаты труда;

5. таким образом, ситуация повторяется на новом витке спирали «зарплата - цены» и т.д.

Следует заметить, что модель инфляционной модели, безусловно, должна рассматриваться на основе заработной платы и совокупного спроса. Это объясняется тем, что в развитых странах заработная плата в общем объеме себестоимости составляет значительную долю (60-70\%), а в России она составляет лишь 20-25\%. Поэтому в нашей экономике инфляционное значение заработной платы невелико.

При этом следует иметь в виду, что если в экономике не действуют антиинфляционные механизмы, то инфляция способна разогнаться вплоть до экономического краха, так как рост цен порождает дальнейший еще больший рост цен. Следует также отметить, что инфляционная спираль раскручивается на основании действия определенных факторов. Эти факторы в основном связаны не столько с инфляцией спроса в сфере обращения, сколько с инфляцией издержек в области производства [5, с. 47].

На наш взгляд, механизм влияния основных факторов на определенные сегменты рынка может быть представлен в виде следующей схемы (рис. 1): 


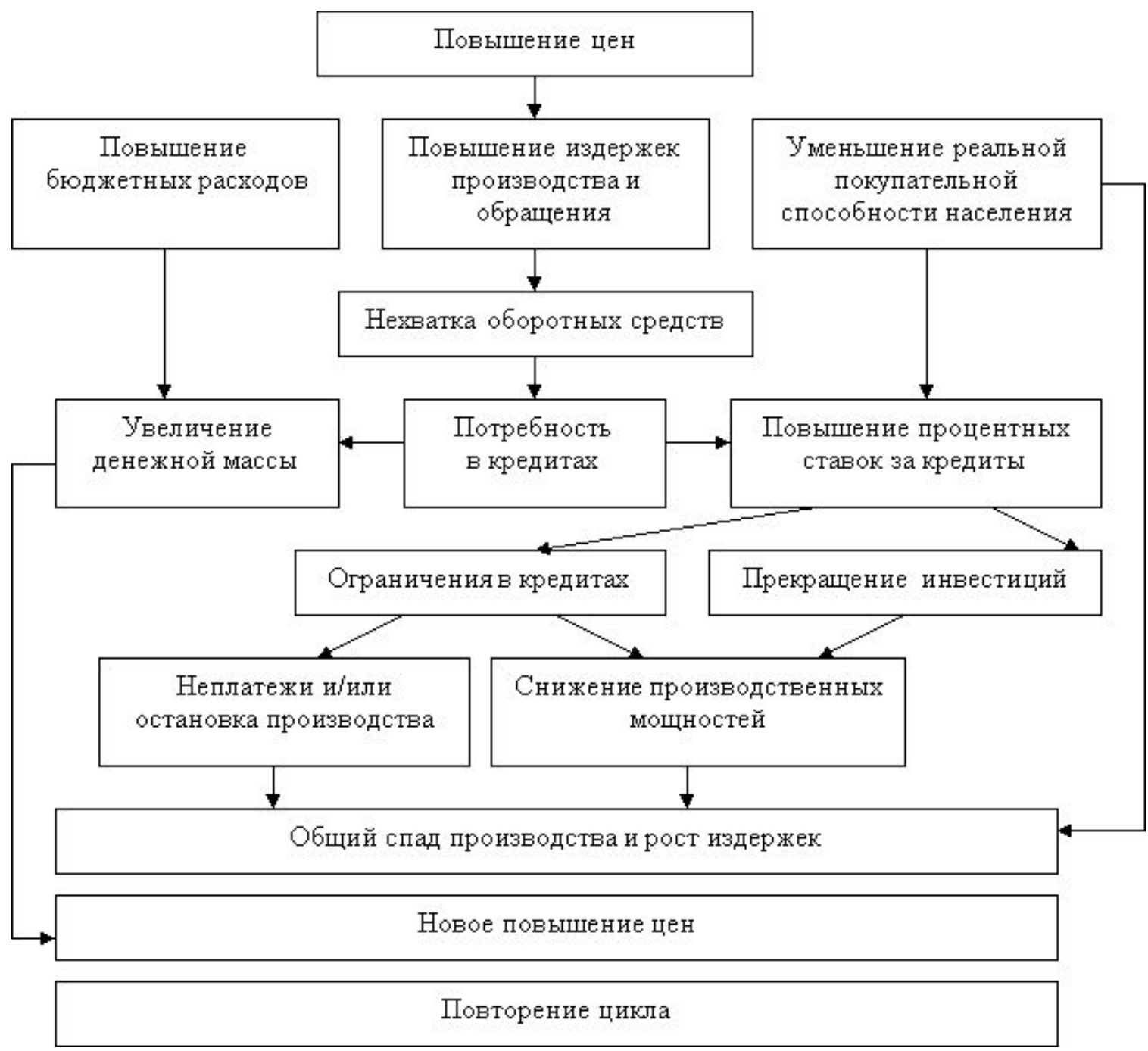

Рис. 1. Схема механизма инфляционной спирали

В чем же всё-таки, состоит несостоятельность теории западной модели инфляционной спирали «заработная плата-цены», которую далее назовём моделью «W- $\mathrm{P} » ?$

Чтобы выяснить некоторые моменты данной проблемы, рассмотрим основные аргументы этой концепции. Наиболее примитивный аргумент, на наш взгляд, заключается в том, что рост заработной платы якобы неизбежно должен вести к повышению цен на товары и услуг.

Как известно из истории экономических учений, еще в середине X1X века в своем научном докладе «Заработная плата, цена и прибыль» К. Маркс доказал, что заработная плата не только теоретически, но и практически может повышаться как за счет увеличения общей массы вновь созданной стоимости, так и за счет лучшего распределения и перераспределения этой стоимо- сти. Однако в обоих случаях, как правило, нет прямой связи заработной платы с ценой продукции.

Западная теория инфляционной спирали «заработная плата - цены» по-нашему мнению порочна не потому, что в действительности якобы нет роста заработной платы, а потому, что она игнорирует объективный закон о необходимости такого роста в соответствии с ростом производительности труда когда цены остаются постоянными. Игнорирование этой объективной закономерности проявляется также и в настоящее время в государственной политике развитых стран, когда они вводят в действие механизм замораживания заработной платы и цен на товары и услуги.

Следует заметить, что ученые - экономисты давно заметили связь, в соответствии с которой инфляция оказывает сильное воздействие на занятость населения. Если рассматривать эмпирические исследования, 
то между уровнем занятости и уровнем инфляции действительно наблюдается определенная связь. При этом получается, что, если безработица высокая, то инфляция держится на низком уровне, и наоборот.

Английский ученый Олбан Ульям Филлипс, инженер по образованию, в своих трудах впервые применил математические методики систем замкнутого контроля к анализу макроэкономических связей. При помощи этой методики Филлипс доказал, что существует зависимость между процентным ростом заработной платы и уровнем безработицы - чем выше уровень роста заработной платы, тем ниже уровень безработицы.

В 1958 году зависимость между уровнем безработицы, ростом заработной платы и цен была предложена Филлипсом в виде графика. Согласно данному графику, падение уровня безработицы по причине роста совокупного спроса вызывает ускорение темпов роста заработной платы, отражая стремление фирм повысить оплату труда своих работников в связи с увеличением спроса на продукцию фирмы. Таким образом, кривая Филлипса предполагает наличие альтернативы — либо безработица, либо инфляция, подталкиваемая спросом.

Ученый использовал в своей работе данные по английской статистике на 1850-1860 годы. Он выстроил специальный график, который наглядно показывает обратную связь изменения ставок заработной платы и уровня показателя безработицы. Следует заметить, что взаимосвязь инфляции и безработицы заключается в том, что при высоком уровне безработицы заработная плата будет держаться на низком уровне, что, несомненно, вызовет медленный рост цен. В соответствии с построенным графиком Филлипс установил, что рост безработицы в Англии более, чем на 2,5-3\% приводит к резкому росту цен и заработной платы.

Кривая Филипса позже была модифицирована американскими учеными-экономистами Самуэльсоном и Солоу. Исходя из того, что теоретически понятия инфляции и безработицы тесно связаны между собой, авторы эмпирически исследовали зависимость уровня занятости и инфляции. Исследователи показали, что инфляция может держаться на низком уровне, если безработица высокая. Кривая Филлипса была изменена с учётом ценовых ожиданий на увеличение заработной платы в денежном выражении.

Как известно, при естественном уровне безработицы темпы инфляции не замедляются, но и не ускоряются. Если государственные власти предпримут меры к снижению безработицы ниже естественного уровня, то тогда уровень инфляции на кривой Филлипса возрастёт.
Если предположить, что темп роста номинальной заработной платы превышает темп объёмов производства на одного человека, тогда уровень безработицы возвращается к своему новому естественному уровню, соответствующему более высокому ожидаемому уровню инфляции. Если власти снова попытаются снизить уровень безработицы, это неизбежно вызовет ускорение инфляции. Вновь возросший уровень зарплаты в денежном выражении подтолкнет уровень безработицы к состоянию «естественного», ещё более высокому ожидаемому темпу инфляции. Чтобы сбить темпы инфляции, власти вынуждены приложить все усилия к временному поддержанию уровня безработицы выше естественного уровня. Нетрудно догадаться, что по мере снижения темпов роста номинальной заработной платы, уровень безработицы постепенно сокращается до своего «естественного» состояния.

В последнее время экономическая нестабильность в странах с рыночной экономикой всё больше обнаруживается в виде, так называемой, стагфляции - это одновременный спад производства и инфляция, в результате чего одновременно растут и цены, и безработица. Дело в том, что, если в прошлом выводы Филлипса подтверждались на практике, то в последнее время наметилась тенденция к сосуществованию безработицы и инфляции вместе. Это привело к попыткам пересмотреть кривую Филлипса, делая некоторые поправки, например, на эффект ценовых ожиданий и т.д.

Следует заметить, что в экономике любой страны действуют факторы, относимые и к инфляции спроса, и к инфляции издержек. Поэтому речь может идти только о преобладании факторов той или иной группы. Инфляция издержек и инфляция спроса взаимосвязаны, поэтому их трудно четко подразделить. Как и инфляция спроса, инфляция издержек имеет механизм самоограничения. Она порождает спад, а спад сдерживает рост издержек. Резкий, непредвиденный рост издержек ведёт к нарушению в механизме предложения, т.е. ведёт к стагфляции сочетанию спада и инфляции. В результате сочетания инфляционного спроса и инфляции издержек возникает инфляционная спираль. Инфляция спроса и инфляция издержектакжевзаимноусиливаютдругдруга. Например, наращивание военных расходов - вызывает инфляцию спроса - растут заработная плата, цены на материалы и услуги - в ответ на рост издержек растут цены фирм требуется новая зарплата и т.д. [3, с. 47].

В результате исследования эффективности действия механизма инфляционной спирали, на наш взгляд, можно сделать следующие выводы:

Инфляция спроса вызывается следующими денежными факторами: 
Таблица 1. Динамика уровня инфляции, безработицы и заработной платы в России за 2001-2020 гг.

\begin{tabular}{|c|c|c|c|c|c|c|c|c|c|c|}
\hline № & годы & $\begin{array}{l}\text { инфл Y } \\
\text { (\%) }\end{array}$ & $\begin{array}{l}\text { безраб X } \\
(\%)\end{array}$ & $\begin{array}{l}\text { зарпл } \mathrm{X}_{I} \\
\text { (\%) }\end{array}$ & $\mathrm{YX}_{1}$ & $\mathrm{YX}_{2}$ & $\mathrm{X}_{1} \mathrm{X}_{2}$ & $\mathbf{X}_{I^{2}}$ & $\mathrm{X}_{2}{ }^{2}$ & $\mathbf{Y}^{2}$ \\
\hline 1. & 2001 & 18.80 & 9.0 & 35.2 & 169.2 & 661.7 & 316.8 & 81.0 & 1239.0 & 353.4 \\
\hline 2. & 2002 & 15.06 & 7.9 & 34.5 & 118.9 & 519.6 & 272.6 & 62.4 & 1190.3 & 226.8 \\
\hline 3. & 2003 & 11.99 & 8.2 & 26.1 & 98.3 & 312.9 & 214.0 & 67.2 & 681.2 & 143.8 \\
\hline 4. & 2004 & \begin{tabular}{|l|}
11.74 \\
\end{tabular} & 7.8 & 22.6 & 91.6 & \begin{tabular}{|l|}
265.3 \\
\end{tabular} & 176.3 & 60.8 & 510.8 & 137.8 \\
\hline 5. & 2005 & 10.91 & 7.2 & 26.9 & 78.6 & 293.5 & 193.7 & 51.8 & 723.6 & 119.0 \\
\hline 6. & 2006 & 9.00 & 7.2 & 24.9 & 64.8 & 224.1 & 179.3 & 51.8 & 669.8 & 81.0 \\
\hline 7. & 2007 & 11.87 & 6.1 & 23.5 & 72.4 & 278.9 & 143.4 & 37.2 & 552.3 & 129.5 \\
\hline 8. & 2008 & 13.28 & 6.3 & 27.2 & 83.7 & 83.7 & 171.4 & 36.7 & 739.8 & 176.4 \\
\hline 9. & 2009 & 8.80 & 8.4 & 8.4 & 73.9 & 73.9 & 70.6 & 70.5 & 70.6 & 77.4 \\
\hline 10. & 2010 & 8.78 & 7.5 & 12.4 & 65.9 & 65.9 & 93.0 & 56.3 & 153.8 & 77.1 \\
\hline 11. & 2011 & 6.10 & 6.6 & 13.1 & 40.3 & 40.3 & 86.5 & 43.6 & 171.6 & 37.2 \\
\hline 12. & 2012 & 6.58 & 5.5 & 12.5 & 36.2 & 36.2 & 68.8 & 30.3 & 156.2 & 43.3 \\
\hline 13. & 2013 & 6.45 & 5.5 & 11.6 & 35.5 & 35.5 & 63.8 & 30.2 & 134.5 & 41.6 \\
\hline 14. & 2014 & 11.36 & 5.2 & 9.1 & 59.1 & 59.1 & 47.3 & 27.1 & 82.8 & 129.0 \\
\hline 15. & 2015 & 12.90 & 5.6 & 5.1 & 72.2 & 72.2 & 28.6 & 31.4 & 26.0 & 166.4 \\
\hline 16. & 2016 & 5.40 & 5.5 & 7.9 & 29.7 & \begin{tabular}{|l|}
29.7 \\
\end{tabular} & 43.5 & 30.3 & 62.4 & 29.2 \\
\hline 17. & 2017 & 2.50 & 5.5 & 6.7 & 13.8 & 13.8 & 36.9 & 30.3 & 44.9 & 6.3 \\
\hline 18. & 2018 & 4.30 & 4.9 & 11.6 & 21.1 & 21.1 & 56.8 & 24.0 & 134.6 & 18.5 \\
\hline 19. & 2019 & 3.00 & 4.9 & 7.5 & 14.7 & 14.7 & 36.8 & 24.0 & 56.3 & 9.0 \\
\hline 20. & 2020 & 4.90 & 5.9 & 5.4 & 28.9 & 28.9 & 31.9 & 34.8 & 29.2 & 24.0 \\
\hline Всего & & 183.7 & 130.7 & 332.2 & 1268.8 & 3131.0 & 2332.0 & 881.7 & 7429.7 & 2026.7 \\
\hline Средн & & 9.19 & 6.54 & 16.61 & 63.44 & 156.55 & 116.6 & 44.09 & 371.49 & 101.34 \\
\hline
\end{tabular}

1. Милитаризация экономики и рост военных расходов.

2. Кредитная экспансия банков.

3. Импортируемая инфляция.

4. Чрезмерные инвестиции в тяжелую промышленность.

Инфляция издержек рассматривается с позиций роста цен под воздействием следующих факторов:

1. Механизм монополистического ценообразования.

2. Снижение роста производительности труда.

3. Спад производства.

4. Возросшее значение сферы услуг.

5. Ускорение прироста издержек и особенно заработной платы в расчёте на единицу продукции.

6. Энергетический кризис.

В ходе исследования мы обнаружили, что в России процесс инфляции осуществляется не в полном соответствии с вышеприведенными теоретическими концепциями. В предпринятом нами исследовании были использованы данные Росстата о темпах инфляции, безработицы и заработной платы в российской экономике за 2001-2020 годы [8, с. 27].

В исследовании нами изучается зависимость уровня инфляции $\mathrm{Y}(\%)$, от уровня безработицы $\mathrm{X}_{I}(\%)$ и тем- пов прироста заработной платы $\mathbf{X}_{2}(\%)$ за 20 лет с 2001 по 2020 год. Для удобства проведения исследования результаты расчётов и промежуточных результатов поместим в таблицу 1.

Таким образом, в результате применения метода наименьших квадратов было получено следующее уравнение множественной регрессии:

$$
y^{*}=-9,7+4,773 x_{1}-0,743 x_{2}
$$

Параметр $\mathrm{a}_{0}=-9,7$ здесь не имеет содержательного смысла и носит чисто расчётный характер. Параметр $\mathrm{a}_{l}=4,773$ (коэффициент линейной регрессии) показывает, что повышение в экономике России уровня безработицы $\left(\mathrm{X}_{1}\right)$ на $1 \%$ при фиксированном (постоянном) значении темпа роста средней заработной платы $\left(\mathrm{X}_{2}\right)$ приводит к повышению уровня инфляции в среднем на 4,773\%. Следовательно, в экономике России, согласно результатам нашего исследования, между уровнем безработицы и уровнем инфляции имеется не обратная, а прямая связь.

Параметр $\mathrm{a}_{2}=-0,743$ означает, что при повышении темпов прироста заработной платы $\left(\mathrm{X}_{2}\right)$ на $1 \%$ при фиксированном (постоянном) значении уровня безработицы уровень инфляции снизится на 0,743\%, т.е. меж- 
ду темпами роста средней заработной платы и уровня инфляции имеется обратная связь, т.е. при повышении заработной платы на 1\%, темп инфляции снизиться на 0,743\%, при повышении заработной платы на 10\%, соответственно, инфляция снизиться на 7,43\% и т.д.

Таким образом, результаты исследования показывают, что в условиях российской рыночной экономики выводы, сделанные учёными, «не работают». Чтобы разобраться в этой проблеме подробнее, продолжим наше исследование.

Сравним влияние факторов $\mathrm{X}_{1}$ и $\mathrm{X}_{2}$ на результат $\mathrm{Y}$ при помощи средних коэффициентов эластичности:

$$
\ni^{*}{ }_{l}=4,773 * 130,7 / 9,19=67,9 ; \ni^{*}=0,743 * 332,2 / 9,19=26,9
$$

Полученные коэффициенты эластичности показывают, что увеличение уровня безработицы (от своего среднего значения) или снижение только темпов роста заработной платы на 1\% увеличивает в среднем уровень инфляции на 67,9\% или 26,9\%. Таким образом, подтверждается большее влияние на уровень инфляции уровня безработицы, чем темпы роста заработной платы.

Найденные в результате исследования коэффициенты парной корреляции: $\mathrm{r}_{y x 1}=0,727 ; \mathrm{r}_{y x 2}=0,097 ; \mathrm{r}_{x 1 x 2}$ $=0,712$ указывают на то, что связь между инфляцией и безработицей весьма сильная, связь между инфляцией и заработной платой весьма слабая, а межфакторная взаимосвязь между безработицей и заработной платой весьма сильная, т.к. $r_{x 1 x 2}=0,712>0,7$. При такой межфакторной зависимости рекомендуется один из факторов исключить из рассмотрения. По нашему мнению, будет исключен фактор $\mathrm{X}_{2}$ (темп роста средней заработной платы).

Чтобы убедиться в этом частные коэффициенты корреляции:

$$
\begin{aligned}
& r_{y x I x 2}=\left(0,727-0,097^{*} 0,712\right) /\left(1-0,097^{2}\right)\left(1-0,712^{2}\right)=0,873 \\
& r_{y x 2 x 1}=\left(0,0,097-0,727^{*} 0,712\right) /\left(1-0,727^{2}\right)\left(1-0,712^{2}\right)=0,321
\end{aligned}
$$

Сравнение коэффициентов парной и множественной корреляции показывает, что из-за высокой межфакторной зависимости коэффициенты парной корреляции дают завышенные оценки тесноты связи. Поэтому из исследования следует исключить фактор $\mathrm{X}_{2}$, у которого теснота парной зависимости меньше, чем теснота межфакторной связи.

Коэффициент множественной корреляции $\mathrm{R}_{y x 1 \times 2}=$ $1-\left(1-0,727^{2}\right)\left(1-0,321^{2}\right)=0,765$ показывает на достаточно сильную связь всего набора факторов с результатом исследования - уровнем инфляции. Такую же оценку надежности полученного в результате нашего исследования уравнения регрессии дает $\mathrm{F}$ - критерий Фишера:

$\mathrm{F}_{\text {факт }}=0,765^{2} /\left(1-0,765^{2}\right)=4,11$, т.е. $\mathrm{F}_{\text {факт }}>\mathrm{F}_{\text {табл }}=3,49$, что означает вероятность случайно получить такое значение $\mathrm{F}$ - критерия не превышает допустимый уровень значимости 5\%. Следовательно, полученное значение не случайно, оно сформировалось под влиянием существенных факторов $\mathrm{X}_{1}$ и $\mathrm{X}_{2}$, т.е. подтверждается статистическая значимость всего уравнения и показателя тесноты связи $\mathrm{R}_{y x 1 x 2}=0,76$.

Если из исследования, как было рекомендовано выше, исключить фактор $\mathrm{X}_{2}$, то можно ограничится уравнением парной регрессии $\mathrm{Y}^{*}=\mathrm{a}_{0}+\mathrm{a}_{1} \mathrm{X}$. Рассчитав параметры, получим уравнение $\mathrm{Y}_{x l}^{*}=4,56+0,708 \mathrm{X}_{l}$. Коэффициент регрессии $\mathrm{a}_{1}=0,708$ указывает на то, что с увеличением среднего уровня безработицы на 1\%, средний уровень инфляции в России возрастет в среднем на $0,708 \%$.

Тесноту линейной связи оценим при помощи коэффициента корреляции

$$
\begin{aligned}
& \mathrm{r}_{x y}=0,708^{*} 1,149 / 4,109=0,21, \text { где } \\
& \mathrm{S}_{x l}=\sqrt{44,09}-6,54^{2}=1,149 ; \\
& \mathrm{S}_{y}=\sqrt{101,34-9,19^{2}=4,109 ;}
\end{aligned}
$$

То, что коэффициент корреляции $\mathrm{r}_{x y}=0,198$ означает, что $21 \%$ вариации уровня инфляции объясняется вариацией уровня безработицы.

В заключение отметим, что из всего вышесказанного можно сделать вывод, что показатель безработицы является одним из ключевых показателей для определения общего состояния экономики для оценки её эффективности. Поэтому все усилия Правительства страны в борьбе с инфляцией должны быть, в первую очередь, направлены на снижение уровня безработицы.

Для противодействия инфляции издержек, которая, по нашему мнению, сейчас существует в нашей экономике, нужно не сдерживать заработную плату, не повышать налоги и проценты на кредит, не стимулировать импорт, наоборот -так как экономика находится на спаде и главная угроза - это безработица и недозагрузка мощностей, государству необходимо стремиться расширить совокупный спрос, увеличить бюджетные расходы и экспорт, снизить проценты на кредит и этим стимулировать производство и занятость. 


\section{ЛИТЕРАТУРА}

1. Кейнс Д.М. Общая теория занятости, процента и денег/ Д.М. Кейнс. Гелиос АРВ, 2002. - 352 с.

2. Бауэр В.П. Инфляция: метрика причин и следствий // В.П. Бауэр. РЭА им. Г.В. Плеханова, 2005. - 56 с.

3. Михайлов А.Г. Социальный аспект инфляции// ЛитРес, 2017. - 21 с.

4. Кизилов В., Сапов Г. Инфляция и её последствия// ЛитРес, 2017. - 45 c.

5. Скосырева Н.П. Регрессионное моделирование инфляционных процессов: монография/ Н.П. Скосырева Н.П. РосНОУ, 2012. -242 с.

6. Ищханов А.В., Линкевич Е.Ф. Инфляционные процессы в новой России: статья// ФиК, 2009. — 43с.

7. Батчаев М.Х.-К. Инфляция и антиинфляционная политика (теория и практика): учебное пособие/ М.Х.-К. Батчаев, Кисловодск, КГтИ, 2004,116 с.

8. Российский статистический сборник// Росстат, M, 2020, 700 c. ISSBN978-5-89476-407-9

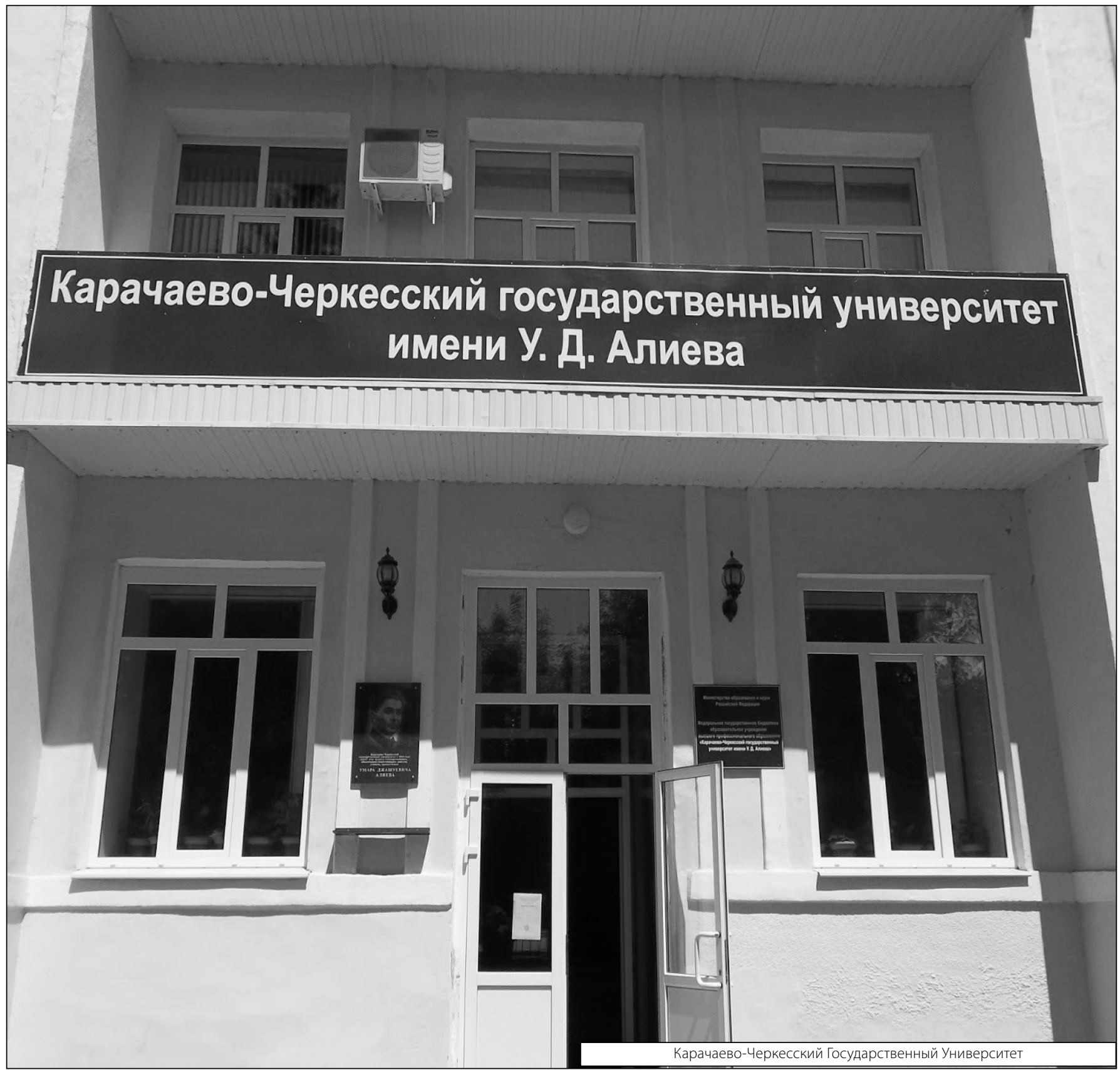

